$\xi=-$ 国

\title{
The Effectiveness of Gamification in Learning Indices and Logarithm
}

\author{
Samsiah Ahmad*, Nurul Hafizah Zainal Abidin, Mahani Ahmad Kardri, Nor Liza Saad \\ Faculty of Computer and Mathematical Science, Universiti Teknologi MARA, Perak Branch, Tapah Campus, \\ Tapah Road, 35400 Perak, Malaysia \\ *Corresponding author E-mail: samsi260@ perak.uitm.edu.my
}

\begin{abstract}
The use of gamification in learning has become a new approach nowadays. This approach helps the learning process to be much more fun and easy to follow. Since students may have some difficulties in understanding the mathematics concepts if they learned using the conventional approach. This paper presents a study on a game development by using the mechanics, dynamics, aesthetic (MDA) framework to study the topic of indices and logarithms. The result shows that student enjoyed the gamification approach and they are able to perform better on the topic of indices and logarithm.
\end{abstract}

Keywords: Gamification; High education; Online game; Virtual learning.

\section{Introduction}

Nowadays, the digital native used digital technology as their main sources for learning and finding the materials. In addition, it is becoming a trend where students are more likely to play game online rather than study mathematics during their leisure time [1]. Therefore, it becomes a challenge for practitioners who use conventional taught for keeping students motivated and engaged especially in mathematics. Some people may have difficulties in learning mathematics [2] due some topic requires the student to memorize and understand concept at the same time. Therefore, the practitioners are acquired to provide a mechanism in developing learning materials, which are more interesting such game in order to motivate and engaged student in learning mathematics [3]. It is an alternative of learning method for young learning. This exacerbates when the practitioners are unable to emphasizing the course based on individual understanding in a classroom distinctly without knowing the different level of mastery and different level of assistance that required by the learners [3]. Hence, education institutions are encouraging the practitioners to provide gamification elements as part of their teaching activities [4]. The emergence of gaming technologies allows the young learners to study indices and logarithm's subject much more fun, easy and interesting environment [3-5]. Therefore, the objective of this paper is to provide the effectiveness of gamification in learning mathematics.

\section{Related work}

Gamification is the strategies that used in contribution to motivate principles and engagement on gaming concepts in learning mathematics [6]. The integration of gamification into learning is one of the techniques to motivate students learning mathematics in a fascinating way [4]. Consequently, the gaming environments will lead to a higher level of commitment and motivation for the learners to [7] involved in any activities that they participated. The government through the ministry of higher education has encour- aged educators to innovate their teaching through gamification which part of the national blue ocean strategy (NBOS). In recent times, there are many researchers and developers are working on learning mathematics through the game environment $[3-4,8]$. The students are unmotivated to use e-learning which results the elearning is not successful to achieve their goals [4]. Therefore, an interactive feature in e-learning is a factor in order to increase the motivation of students to learn mathematics in such interesting approaches [9-11].

The gamification elements are based on the mechanics, dynamics and aesthetic (MDA) framework which able to produce the desired physiological and behavior [12]. This paper presents the used of MDA framework in developing the game in learning mathematics, so that the end product is fun and may help the student perform in this topic. The elements that are implemented in this game are in line with the education learning objective. In the game, students need to achieve some specific goals with the presence of few obstacles while in education learning, they need to perform specific activities or interaction with educational content.

\section{Methodology}

\subsection{Gamification framework}

The development of an effective strategy in implementing gamification in learning mathematics is vital to achieve the learning outcome. Therefore, the MDA framework has been used in designing the gamification for learning indices and logarithm. There are three elements of gamification, which are the game mechanics, dynamic and aesthetics as in Table 1. An online survey has been conducted to evaluate and identify the effectiveness of implementing gamification in learning indices and logarithm. 
Table 1: Elements of gamification

\begin{tabular}{|c|c|c|}
\hline Game Mechanics & Game Dynamic & Aesthetics \\
\hline Points & Reward & satisfaction \\
Level & Status & pleasure \\
Challenges & Achievement & envy \\
Badges, gifts and charity & competition & respect \\
\hline
\end{tabular}

\subsection{Game development}

The earlier research [3] state that gaming approach for higher education failed due to artistic animation tools that is not attractive in the lessons. Therefore, in this paper, we designed a game environment for learning mathematics using MDA framework. There are several elements that have been used in designing the game.

\subsubsection{Rewarding}

Rewarding is an important element in developing the game because it engages student literally in learning indices and logarithm. Reward are given as an appreciation and achievement when players (students) scored in the game. Indirectly, it gives an attraction to involve students in learning activities which are more fun and excitement. This elements contribute in developing a repetition behavior for students to repeat playing the game $[8,11,14]$. In this project, this element has been provided through points and score during playing games.

\subsubsection{Challenging}

As human, they are driven by accomplishment when getting through a challenging stage [14]. In this game, players need to go through few obstacles where each obstacle are indices and logarithms questions. The questions have different level of difficulties which are easy, medium and difficult. Each level is provided with the points as reward for the users when involved in the gaming activities.

\subsubsection{Status}

In this game, it provides the element of status because most of the people need to be recognized, fame, prestige, attention and respect from others. Therefore, this project has provided the status for the player in this game when they accomplish for each difficulties level. For example, if the completing easy level the player will have status as beginner, medium as amateur and difficult as expert $[2,14]$.

\subsubsection{Competition}

The element allows students to compete among themselves to the highest level in the game activities. Then, the winner will be given reward. These mechanism allows the learners to challenge themselves to compete among players in accomplishing each level This affect the learners more excitement to indices and logarithm in fun and interesting approaches.

The game has been developed based on those elements in order to provide the interesting methodologies in learning indices and logarithm to be more easy and fun. These games also provide learning materials through video animation to understand the conceptual and rules of indices and logarithm. This game has been developed based on gamification framework, that associate with non-game elements. Therefore, the game has been developed as shown on Figure 1-4.

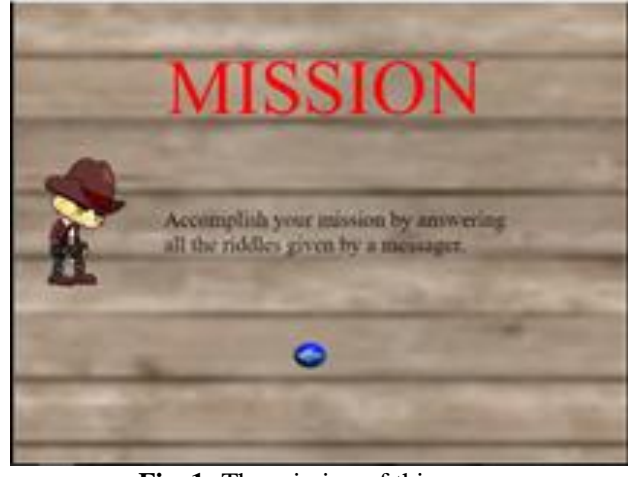

Fig. 1: The mission of this game

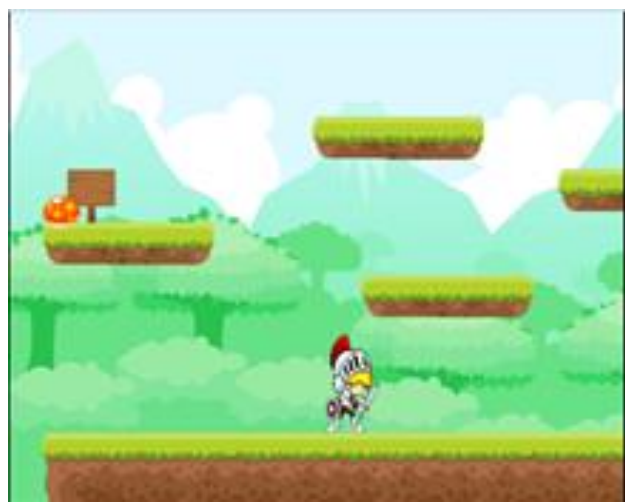

Fig. 2: Game activities

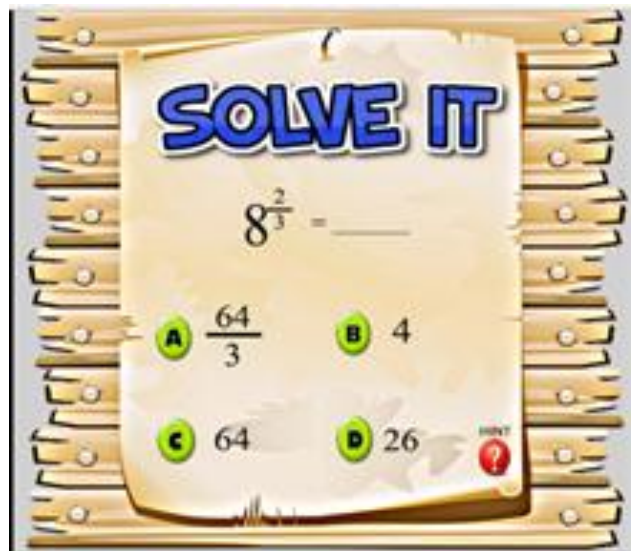

Fig. 3: Game question

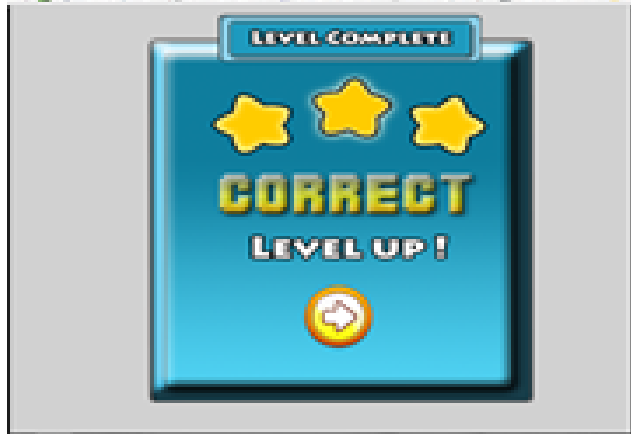

Fig. 4: Game leve

\section{Results and discussion}

To ensure that the gamified approach helps students in learning, an online survey was done to evaluate the student's acceptance on the game and a written evaluation where students were asked to answer few questions on indices and logarithms.

Respondents from a group of diploma students $(\mathrm{N}=100)$ was given a written test on the topic. These students have already learned the topic beforehand. Students were given an hour to an- 
swer a set of 100 marks of questions. Later, the same group of students was introduced to the developed game. There were given a week to engage with the game and indirectly, learn the topic by playing the game. After a week, a new set of questions but with the same level of difficulty as previous was given to these students

\subsection{Students feedback on gamification}

A general observation on the interface has been evaluated among the students. The rate scores are from 1 to 4 where score 1 represents 'below standard', score 2 represents 'needs improvement', score 3 represents 'satisfactory' and score 4 represents 'excellent'. Following [13], the basic observation item is text, graphic and music. Table 2 shows that the overall performance of the game application was excellent by $72.14 \%$ and no respondents rate the video below standard for each item. The rating score for satisfactory was $22.3 \%$ and $5.56 \%$ students believe that the game development needs some improvement. Respondents are also welcome to give any general comments that can be considered when we enhanced the feature and improve the game development.

\begin{tabular}{|c|c|c|c|c|}
\hline Item & $\begin{array}{c}\text { Below } \\
\text { Standard } \\
\text { Score: } 1 \\
\end{array}$ & $\begin{array}{c}\text { Needs Im- } \\
\text { provement } \\
\text { Score: } 2\end{array}$ & $\begin{array}{l}\text { Satisfactory } \\
\text { Score: } 3\end{array}$ & $\begin{array}{c}\text { Excellent } \\
\text { Score: } 4\end{array}$ \\
\hline Text & 0 & $2.6 \%$ & $12.3 \%$ & $85.1 \%$ \\
\hline Colour & 0 & $4 \%$ & $15.8 \%$ & $80.2 \%$ \\
\hline Music & 0 & $3.5 \%$ & $18.8 \%$ & $77.7 \%$ \\
\hline $\begin{array}{l}\text { Reward } \\
\text { element }\end{array}$ & 0 & $12.8 \%$ & $52 \%$ & $35.2 \%$ \\
\hline $\begin{array}{c}\text { Challenging } \\
\text { element }\end{array}$ & 0 & $5 \%$ & $22 \%$ & $73 \%$ \\
\hline $\begin{array}{c}\text { Status ele- } \\
\text { ment }\end{array}$ & 0 & $6.1 \%$ & $20.1 \%$ & $73.8 \%$ \\
\hline $\begin{array}{c}\text { Competition } \\
\text { element }\end{array}$ & 0 & $4.9 \%$ & $15.1 \%$ & $80 \%$ \\
\hline $\begin{array}{l}\text { Overall per- } \\
\text { formance }\end{array}$ & 0 & $5.56 \%$ & $22.3 \%$ & $72.14 \%$ \\
\hline
\end{tabular}

The text in the game is rated $85.1 \%$ excellent since the font size is large and suitable for viewing. No fancy font was used and the font used is readable for players. For the colour item, the score is higher which is $80.2 \%$ compared to satisfactory $15.8 \%$ and needs improvement $4 \%$. The colour used is suitable as can be seen from the Figure 1-4. The game is designed so that the sound (music) can be switch on or off. However, the volume is standard as students still can control the volume from their electronic devices. Music used in this game is energetic as to attract players and boost their energy. They rated $77.7 \%$ for excellent music choice, $18.8 \%$ for satisfactory and $3.5 \%$ needs improvement.

The online survey also takes into consideration the four elements that were integrated into this game. Each element was explained thoroughly to the respondents, so that they are clear to evaluate the game based on the elements criteria. The basic criteria for a game development, is the rewarding elements. For each successful action playing the game or answering the question in the game, players will be given scores or marks. Since maybe this element can also be seen in other games, respondents rated 52\% as satisfactory as the highest rate. Three level of difficulty was developed in this game. The level depends on the type of questions asked. In the easiest level, most questions asked about the concept of indices and logarithm. The second level asked on the applications of concept and lastly, the third level needs some analysis or calculations before answering the question. Students prefer the challenging element as this element guide them by step. The level also builds up their confidence once passed a level and this motivates them to move to the next level which is more challenging. Respondents rated $73 \%$ excellent, $22 \%$ satisfactory and $5 \%$ needs improvement.

The status element was rated highest as excellent by $73.8 \%$, satisfactory by $20.1 \%$ and needs improvement by $6.1 \%$. It is logical as students in the teenage age prefer something that gives them recognition and attention from others. The last element that was evaluated is the competition element. Most students enjoy this element compared to other elements since students like to challenge themselves and compare their achievement with others. Most students enjoy this element compared to other elements since students like to challenge themselves and compare their achievement with others

\subsection{Effectiveness of gamification}

A different new set of questions but with the same level of difficulty as previous was given to the same group of students. The results have obtained from the test is shown in Table 3 .

Table 3: Test results

\begin{tabular}{|l|c|c|c|c|c|c|}
\hline & \multicolumn{3}{|c|}{ Pre-test } & \multicolumn{3}{c|}{ Post-test } \\
\hline \multicolumn{1}{|c|}{ Marks } & $1-49$ & $50-79$ & $\begin{array}{c}80- \\
100\end{array}$ & $1-49$ & $50-79$ & $\begin{array}{l}80- \\
100\end{array}$ \\
\hline Indices & $35 \%$ & $45 \%$ & $20 \%$ & $9 \%$ & $25 \%$ & $66 \%$ \\
\hline Logarithm & $21 \%$ & $62 \%$ & $17 \%$ & $5 \%$ & $20 \%$ & $75 \%$ \\
\hline $\begin{array}{l}\text { Combination } \\
\text { of indices and } \\
\text { logarithms }\end{array}$ & $40 \%$ & $31 \%$ & $29 \%$ & $13 \%$ & $37 \%$ & $50 \%$ \\
\hline
\end{tabular}

The result shows that students obtained better results in both topics. For example, in indices topic, students that score between 149 decreased from $35 \%$ to $9 \%$. In other words, the failure rate for this topic becomes lower. The average score 50-79 is decreased from $45 \%$ to $25 \%$ and the excellent score $80-100$ increased from $20 \%$ to $66 \%$. In logarithms, the results are better compare to indices where the excellent score $80-100$ increased from $17 \%$ to $75 \%$. Similar results were shown in questions that combine both indices and logarithm properties, where the students' performance increases from $29 \%$ to $50 \%$. This indicates that students did learn through the game and they did improve their understanding of the topics.

\section{Conclusion}

Gamification is an alternative approach in learning mathematics. The features in the game such as rewarding, challenging, status and competitions had given a mechanism to develop a good game and hence build the interest to learn in an interesting and fun way. The study shows that game education provides significant impact in improving students' performance of indices and logarithm topics. The students accept and engage well with the new way of learning technique. Therefore, in future, elements of the game applications will be continuously improvised by inserting other cognitive elements that suit with student level of understanding.

\section{Acknowledgement}

We would like to thank Faculty of Computer and Mathematical Science for allowing to conduct the survey among students and acknowledge the financial support received from Universiti Teknologi MARA under ARAS 600-IRMI/DANA 5/3/ARAS (0188/2016) grant.

\section{References}

[1] Erenli K (2013), The impact of gamification, Emerging Technology Learning 8, 15-21.

[2] Fotaris P, Mastoras T, Leinfellner R \& Rosunally Y (2016), Climbing up the leaderboard: An empirical study of applying gamification techniques to a computer programming class, E-Learning 14(2), 94-110.

[3] Faghihi U, Brautigam A, Jorgenson K, Martin D, Brown A, Measures E \& Bouchard SM (2014), How gamification applies for educational purpose specially with college algebra, Procedia Computer Science 41, 182-187.

[4] Nah FFH, Zeng Q, Telaprolu VR, Ayyappa AP \& Eschenbrenner B 
(2014), Gamification of education: A review of literature, HCI in Business, 401-409.

[5] Gené OB, Núñez MM, \& Blanco ÁF (2014), Gamification in MOOC: Challenges, opportunities and proposals for advancing MOOC model, Proceedings of the Second International Conference on Technological Ecosystems for Enhancing Multiculturality, 215-220.

[6] Amir Fazamin WM, Hamzah W, Ali NH, Mohd Saman MY, MH Yusoff \& Yacob A (2015), Gamification, influence of gamification on students motivation in using e-learning applications based on the motivational design model, Emerging Technology Learning 10, 30 34.

[7] Lopez GM \& López G (2007), Computer support for learning mathematics: A learning environment based on recreational learning objects, Computer Education 48, 618-641.

[8] Yildirim I (2017), The effects of gamification-based teaching practices on student achievement and students' attitudes toward lessons, Internet High Education 33, 86-92.

[9] El-Seoud M, Samir A, El-Sofany, Hosam F; Taj-Eddin, Islam ATF Nosseir A, El-Khouly \& Mahmoud M (2013), Implementation of web-based education in Egypt through cloud computing technologies and its effect, Higher Education Studies 3,62-76.

[10] Alsawaier RS (2017), The effect of gamification on motivation and engagement, Information and Learning Technology 35, 56-79.

[11] Randel JM, Morris BA, Wetzel CD \& Whitehill B. V (1992), The effectiveness of games for educational purposes: A review of recent research, Simulation and Gaming 23, 261-276.

[12] Harms J, Wimmer C, Kappel K \& Grechenig T (2014), Gamification of online surveys: Conceptual foundations and a design process based on the MDA framework, Proceedings of the 8th Nordic Conference on Human-Computer Interaction: Fun, Fast, Foundational, pp. 565-568.

[13] Trujillo K, Chamberlin B, Wiburg K \& Armstrong A (2016), Games evolution: Review of methodologies used in determining effectiveness of math snacks games and animations, Technology Knowledge Learning 21,155-174.

[14] Seixas RL, Gomes AS \& Filho IJM (2016), Effectiveness of gamification in the engagement of students, Computer Human Behavior 58, 48-63. 